\title{
The value of percutaneous cholangiography
}

\author{
GORDON EVISON \\ M.B., F.F.R.
}

\author{
Myles MCNulty \\ M.B., F.F.R.
}

\author{
Colin Thomson \\ M.C., M.B., D.M.R.D.
}

\section{Department of Radiology, Royal United Hospital, Bath, Somerset}

\section{Summary}

Percutaneous cholangiograms performed on fifty patients in a district general hospital have been reviewed, and the advantages and limitations of the examination are described. The investigation is considered to have sufficient diagnostic value to warrant its inclusion in the diagnostic armamentarium of every general radiological department.

SINCE the introduction in this country of percutaneous trans-hepatic cholangiography using a flexible catheter (Shaldon, 1962; Shaldon, Barber \&
Young, 1962) its value has been assessed in a number of publications from this country, the United States and Sweden. In recent surveys of the radiology of jaundiced patients (Gleeson, 1970; Williams, 1970; Dawson, 1970) the value of the procedure is acknowledged. Most of the reviews, however, have come from teaching centres, and we thought that it would be useful to present our experience with this technique in the context of a district general hospital.

\section{Method}

The technique adopted is that described by Shaldon

TABLE 1. Comparison of preoperative, cholangiography and laparotomy diagnoses

\begin{tabular}{|c|c|c|c|c|c|}
\hline \multirow{3}{*}{\multicolumn{2}{|c|}{\begin{tabular}{ll} 
& \multicolumn{1}{c}{$\begin{array}{c}\text { Clinical } \\
\text { diagnosis }\end{array}$} \\
1. & Extra-hepatic obstruction \\
& Ca. \\
& Stones \\
(19 cases)
\end{tabular}}} & \multicolumn{2}{|c|}{$\begin{array}{l}\text { PTHC } \\
\text { diagnosis }\end{array}$} & \multicolumn{2}{|l|}{$\begin{array}{l}\text { Surgical/autopsy } \\
\text { diagnosis }\end{array}$} \\
\hline & & EHO & (14) & $\begin{array}{l}\text { Ca. pancreas } \\
\text { Stones }\end{array}$ & $\begin{array}{r}(11) \\
(3)\end{array}$ \\
\hline & & No EHO & (5) & $\begin{array}{l}\text { Hepatitis } \\
\text { Chlorpromazine } \\
\text { jaundice } \\
\text { Liver secondaries }\end{array}$ & $\begin{array}{l}(1) \\
(2)\end{array}$ \\
\hline \multirow[t]{2}{*}{2.} & $\begin{array}{l}\text { Ca. pancreas } \\
\text { (17 cases) }\end{array}$ & EHO & (11) & $\begin{array}{l}\text { Ca. pancreas } \\
\text { Ca. gall bladder } \\
\text { Ca. CBD }\end{array}$ & $\begin{array}{l}\text { (9) } \\
(1) \\
(1)\end{array}$ \\
\hline & & No EHO & (6) & $\begin{array}{l}\text { Ca. pancreas } \\
\text { Ca. gall bladder } \\
\text { Inflammatory mass } \\
\quad \text { in pancreas } \\
\text { Stone in CBD } \\
\text { Infectious hepatitis }\end{array}$ & $\begin{array}{l}(1) \\
(1) \\
(2) \\
(1) \\
(1)\end{array}$ \\
\hline 3. & $\begin{array}{l}\text { Stricture CBD } \\
\quad(3 \text { cases })\end{array}$ & $\begin{array}{l}\text { Strictures } \\
\text { demonstrated }\end{array}$ & (3) & Strictures in CBD & (3) \\
\hline \multirow[t]{2}{*}{4.} & $\begin{array}{r}\text { Gallstones } \\
\text { (6 cases) }\end{array}$ & EHO & (5) & $\begin{array}{l}\text { Ca. pancreas } \\
\text { Stones }\end{array}$ & $\begin{array}{l}\text { (2) } \\
\text { (3) }\end{array}$ \\
\hline & & No EHO & (1) & Pancreatic abscess & (1) \\
\hline 5. & $\begin{array}{l}\text { EHO } \\
\text { Cirrhosis } \\
\quad(2 \text { cases })\end{array}$ & EHO & (2) & $\begin{array}{l}\text { Ca. CBD } \\
\text { Stricture CBD }\end{array}$ & $\begin{array}{l}\text { (1) } \\
\text { (1) }\end{array}$ \\
\hline 6. & $\begin{array}{l}\text { Infectious hapatitis } \\
\quad(3 \text { cases) }\end{array}$ & EHO & (3) & $\begin{array}{l}\text { Stones in CBD } \\
\text { Ca. in CBD } \\
\text { Ca. pancreas }\end{array}$ & $\begin{array}{l}\text { (1) } \\
\text { (1) } \\
\text { (1) }\end{array}$ \\
\hline
\end{tabular}

PTHC, percutaneous transhepatic cholangiogram; CBD, common bile duct; EHO, extrahepatic obstruction; Ca., carcinoma. 
et al. (1962), using a flexible polythene catheter and the anterior abdominal approach. Patients were referred by both physicians and surgeons, but were in all cases prepared for subsequent laparotomy, and by prior agreement this was performed regardless of the result of the procedure.

\section{Results}

The results of fifty cases are presented in tabular form. Table 1 compares the pre-operative diagnosis with the cholangiogram and laparotomy diagnosis. In the forty-five cases thought clinically to have extra-hepatic obstruction, the cholangiogram confirmed this in thirty-three, and this was further confirmed at laparotomy. In the remaining twelve cases where there was no cholangiographic evidence of extra-hepatic obstruction, six were due to hepatitis or liver secondaries and three to chronic pancreatitis or pancreatic abscesses without obstruction, but the remaining three did have extra-hepatic obstruction.

From Table 2, which contrasts the results of the cholangiogram for dilated and not dilated intrahepatic ducts, it can be seen that the three cases with extra-hepatic obstruction where the puncture failed (marked with an asterisk) did not have dilated intrahepatic ducts, though the common bile duct in these cases was noted to be distended. This would seem to provide some justification for our policy of restrict- $\mathbb{Q}$ ing trans-hepatic cholangiograms to those cases $c$ where laparotomy had already been decided upon on $\ddot{\Rightarrow}$. clinical criteria. The five cases which were thought $\stackrel{?}{+}$ clinically to be non-obstructive (Groups 5 and 6 in Table 1) showed features later in their course, either clinically or after liver biopsy, which suggested extra

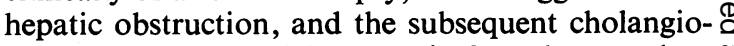
gram showed that all five were in fact obstructed. in

Table 3 shows the results of the cholangiograms $\vec{\circ}$ in the ten patients who underwent liver biopsy. Interpretation of abnormal liver histology depends much upon the experience of the individual pathologists in this field.

\section{Discussion}

(1) Although the procedure is said to be technically ov difficult and require additional radiographic facilities, or we have not found this to be the case. The technique $\stackrel{\omega}{~}$ is relatively simple and easily acquired, and the equipment is standard; image intensification and $\frac{\circ}{5}$ television being very useful, but not essential. The $\overrightarrow{C D}$ only staff required are one radiologist, a nurse or $\mathbb{D}$ assistant, and the radiographer.

(2) We have not found that patients suffer undue

\begin{tabular}{|c|c|c|c|c|c|}
\hline \multicolumn{3}{|c|}{ Dilated } & \multicolumn{3}{|c|}{ Not dilated } \\
\hline $\begin{array}{c}\text { Puncture } \\
\text { success }(37 \text { case }\end{array}$ & & $\begin{array}{c}\text { Puncture } \\
\text { failure (1 case) }\end{array}$ & $\begin{array}{c}\text { Puncture } \\
\text { success }(2 \text { cases })\end{array}$ & $\begin{array}{c}\text { Puncture } \\
\text { failure (10 cases) }\end{array}$ & \\
\hline $\begin{array}{l}\text { Ca. pancreas } \\
\text { Stones in CBD } \\
\text { Strictures in CBD } \\
\text { Ca. CBD } \\
\text { Ca. gall bladder }\end{array}$ & $\begin{array}{r}23 \\
6 \\
4 \\
3 \\
1\end{array}$ & $\begin{array}{c}\text { Stone in CBD } \\
\text { (bile obtained } \\
\text { but no injection) }\end{array}$ & $\begin{array}{c}\text { Both } \\
\text { hepatitis }\end{array}$ & $\begin{array}{l}\text { Hepatitis } \\
\text { Chlorpromazine } \\
\text { jaundice } \\
\text { Liver secondaries } \\
\text { Ca. gall bladder* } \\
\text { Stone in CBD* } \\
\text { Ca. pancreas* } \\
\text { Chronic inflammatory } \\
\text { mass in pancreas } \\
\text { Pancreatic abscess }\end{array}$ & $\begin{array}{l}2 \\
1 \\
1 \\
1 \\
2\end{array}$ \\
\hline
\end{tabular}

* Extra-hepatic obstruction (see text). Ca., carcinoma; CBD, common bile duct.

TABLE 3.

\begin{tabular}{rlll}
\hline \multicolumn{1}{c}{ Liver biopsy } & PTHC & \multicolumn{1}{c}{ Surgical diagnosis } \\
\hline 1. & $\begin{array}{l}\text { No large bile duct } \\
\text { obstruction }\end{array}$ & EHO & Ca. pancreas \\
\hline 2. & Large bile duct obstruction & EHO & Ca. pancreas \\
3. Large bile duct obstruction & EHO & Ca. pancreas \\
4. Large bile duct obstruction & EHO & Ca. pancreas \\
5. Large bile duct obstruction & EHO & Ca. pancreas \\
6. Large bile duct obstruction & EHO & Stones in CBD \\
7. Large bile duct obstruction & EHO & Stones in CBD \\
8. Large bile duct obstruction & No EHO & Ca. gall bladder \\
9. Large bile duct obstruction & No EHO & Hepatitis (chlorpromazine) \\
10. Large bile duct obstruction & No EHO & Hepatitis \\
\hline
\end{tabular}

TABLE 2. Calibre of intrahepatic ducts at operation 


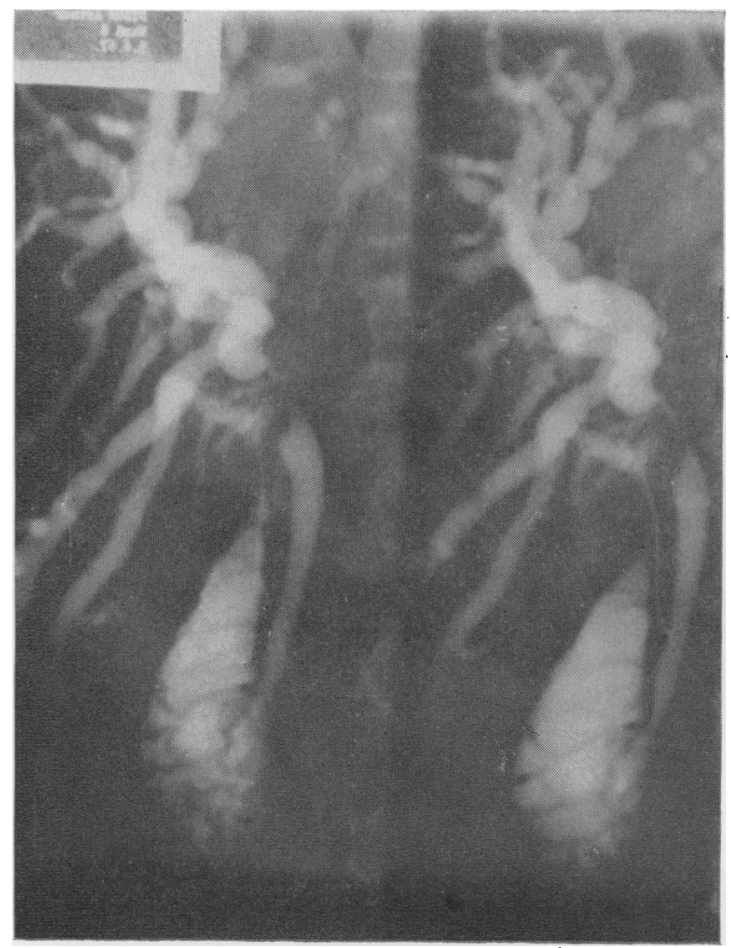

Fig. 1. Stricture of the common bile duct following previous surgery.

discomfort during the procedure, though this does depend to a large extent on the radiologist. The patient should be well sedated (care being taken if there is significant liver disease) and ample local anaesthetic injected. Under these conditions the procedure should be no more uncomfortable than, say, a lumbar puncture.

(3) The distinction between intra-hepatic and extra-hepatic cholestasis may be extremely difficult clinically. This becomes apparent from a comparison of the pre-operative clinical diagnosis with the laparotomy diagnosis in Table 1 . The additional information provided by the percutaneous cholangiogram materially increases the accuracy of the preoperative diagnosis.

(4) The fact that all the patients subsequently underwent laparotomy does not obviate the need for a pre-operative cholangiogram, for several reasons. Where strictures have to be demonstrated, the cholangiogram provides a reliable guide when, as often happens, detail at laparotomy is obscured by adhesions from previous surgery (Fig. 1). The length of duct available for anastomosis in carcinoma of the pancreas is shown. Sometimes a carcinoma arising primarily in the common bile duct, with a better prognosis, can be demonstrated (Fig. 2). In

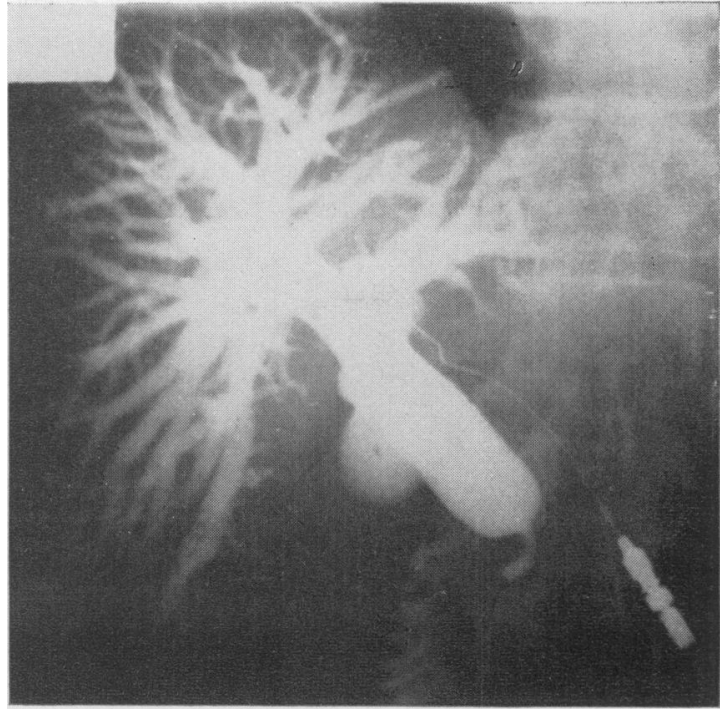

FIG. 2. Carcinoma of the common bile duct showing symmetrical encircling stricture.

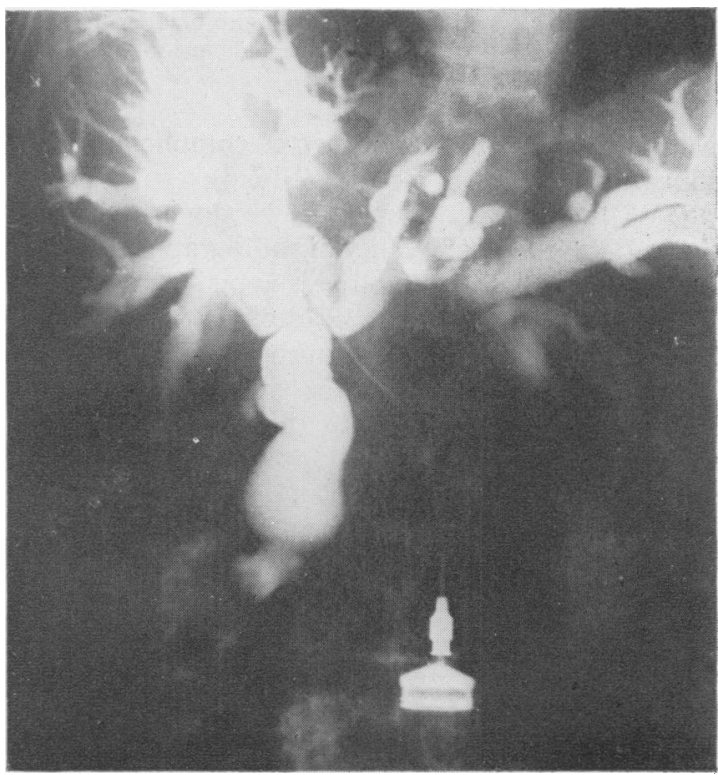

FIG. 3. Stone in the common bile duct thought at laparotomy to be a carcinoma.

one of our cases, with a clinical diagnosis of carcinoma, a stone was present in the lower end of the common bile duct and surrounded by induration, which felt at laparotomy like a carcinoma (Fig. 3). An anastomosis was only prevented by the demonstration of the stone on the cholangiogram, the stone subsequently being removed with full recovery of the 


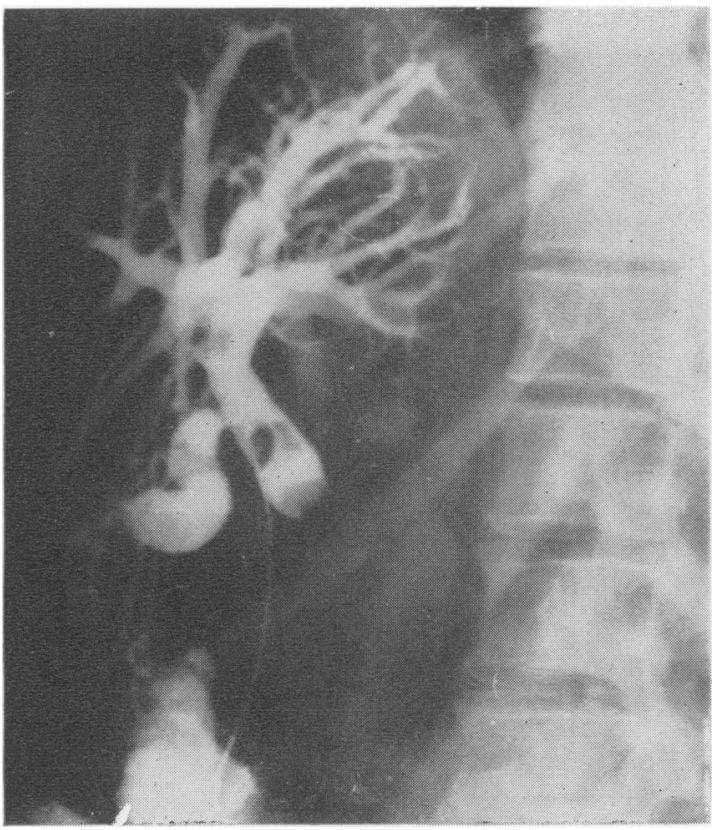

FIG. 4. Stones in the bile ducts and gall bladder with a cholecysto-colic fistula, unsuspected prior to the cholangiogram.

patient. Occasionally, unsuspected complications are shown on the cholangiogram (Fig. 4).

(5) The cholangiogram must be done pre-operatively. The technical quality of radiographs obtained in the operating theatre is not as good as those which can be obtained in the Radiology Department. Small carcinomata situated in the hepatic duct may be missed at laparotomy; these are more likely to be shown on a percutaneous than on an operative cholangiogram.

(6) Ideally, a negative cholangiogram should save the patient from an unnecessary laparotomy. A negative cholangiogram may be: (a) one in which az normal duct system is inadvertently punctured and $\underset{\mathcal{Q}}{\mathbb{Q}}$ shown to be normal; in these cases laparotomy would. . not be indicated; (b) where a given number of $\overrightarrow{\vec{F}}$ punctures (we limit this to five) have been unsuccess-? ful in aspirating bile. Unfortunately, in ten cases of? puncture failure in this category (Table 2) three were $\frac{\bar{\sigma}}{\bar{c}}$. due to extra-hepatic obstruction (asterisks), so that $\frac{\text { क }}{\widetilde{R}}$ this criterion is not reliable in assessing the need for $\cong$ laparotomy.

\section{Conclusions}

Percutaneous trans-hepatic cholangiography is an $\vec{\omega}$ investigation which should be available in everydistrict general hospital. It should only be done $\frac{0}{3}$ prior to laparotomy. If the bile ducts are dilated, it gives a good radiographic demonstration of the site $c$ of the obstruction. Failure to puncture a duct means $y$ that the ducts are almost certainly not dilated, but or unfortunately this does not necessarily mean that $\mathcal{G}^{-}$ there is no extra-hepatic obstruction.

\section{Acknowledgments}

We thank the physicians and surgeons on the staff of the Royal United Hospital, Bath, for referring their patients to us, and the radiographic and nursing staff for their assistanc. $\bar{\sigma}$ We are also grateful to Miss M. Plimer and Miss S. B. Davies for the typescript and to Mr N. L. Gay for the illustration $\overrightarrow{0}$

\section{References}

Dawson, J.L. (1970) Surgical aspects of jaundice. British Medical Journal, 1, 228.

GleEson, J.A. (1970) Radiology in the jaundiced patient. British Journal of Hospital Medicine, 3, 713.

Shaldon, S. (1962) The investigation of bile ducts by percutaneous cholangiography. Proceedings of the Royal Society of Medicine, 55, 587.

Shaldon, S., Barber, K.M. \& Young, W.B. (1962) Percutaneous transhepatic cholangiography-a modified technique. Gastroenterology, 42, 371.

Williams, R. (1970) Medical aspects of jaundice. British Medical Journal, 1, 225. 